Received 02/06/2020 Review began 02/27/2020 Review ended 03/02/2020 Published 03/03/2020 Retracted 04/14/2021

(c) Copyright 2020

Martin et al. This is an open access article distributed under the terms of the Creative Commons Attribution License CC-BY 4.0 which permits unrestricted use, distribution, and reproduction in any medium, provided the original author and source are credited.

\section{Retracted: Uterine Inversion Secondary to a Large Prolapsed Leiomyoma: Diagnostic and Management Challenges}

Anastasia Martin ${ }^{1}$, Anastasios Tranoulis ${ }^{2}$, Ahmad Sayasneh ${ }^{3}$

1. Obstetrics and Gynaecology, King's College London - School of Medicine, London, GBR 2. Gynaecological Oncology, Guy's and St Thomas' NHS Foundation Trust, London, GBR 3. Gynaecological Oncology, Guy's and St Thomas' Nhs Foundation Trust, London, GBR

Corresponding author: Anastasia Martin, anastasia.martin@kcl.ac.uk

\section{This article has been retracted.}

Retraction date: April 14, 2021. Cite this retraction as Martin A, Tranoulis A, Sayasneh A (April 14, 2021) Retraction: Uterine Inversion Secondary to a Large Prolapsed Leiomyoma: Diagnostic and Management Challenges. Cureus 13(4): r29. doi:10.7759/cureus.r29.

This article has been retracted and removed due to a formal request from the authors made at the behest of the patient featured in the case. No evidence of any author misconduct has been found, however, the authors wish to honor the patient's request. The retraction request from the authors has been included below:

As the most senior academic author on the paper, and in agreement with my other co-authors, we formally wish to request the retraction of this published article. We have reached this sad decision after long discussions among ourselves as authors and after consulting the academic board in the Gynaecological Oncology Department at Guy’s and St Thomas’ NHS Foundation Trust.

Our patient gave consent for her case report to be published while she was in the hospital after a successful surgery and excellent recovery. The initial consent form signed was the surgical consent for the procedure itself which allowed us to take photos for teaching and the second informed written consent form was a standard form for publication in a journal. At that time she was very happy for the case to be published. A year and a half later she wrote to me expressing that although she signed the consent form she did not read the article before publication and she requested a copy of the publication. Later she wrote expressing her wish for the publication to be withdrawn based on that she did not consent for this particular paper. Different reasons were given in subsequent conversations but she remained adamant that the paper be removed.

Although some might argue that we can challenge these allegations, our ethical commitment to good clinical practice and putting patients first has led us to formally request the retraction of this article.

\section{Abstract}

Retracted

Categories: Obstetrics/Gynecology

Keywords: non-puerperal uterine inversion, leiomyoma

Introduction

Retracted

Case Presentation

Retracted

Discussion

Retracted

\section{Conclusions}

Retracted 


\section{Cureus}

\section{Additional Information \\ Disclosures}

Human subjects: Consent was obtained or waived by all participants in this study. Conflicts of interest: In compliance with the ICMJE uniform disclosure form, all authors declare the following: Payment/services info: All authors have declared that no financial support was received from any organization for the submitted work. Financial relationships: All authors have declared that they have no financial relationships at present or within the previous three years with any organizations that might have an interest in the submitted work. Other relationships: All authors have declared that there are no other relationships or activities that could appear to have influenced the submitted work. 